\title{
Clinicopathologic characteristics and prognosis of upper tract urothelial carcinoma complicated with aristolochic acid nephropathy after radical nephroureterectomy
}

\author{
Hongli Shan', Wen Tian², Yazhao Hong ${ }^{3}$, Bo Xu ${ }^{3}$, Chunxi Wang ${ }^{3}$, Bing Yu ${ }^{3^{*}}$ and Xiaoqing Wang ${ }^{3^{*}}$ (D)
}

\begin{abstract}
Background: The purpose of this study was to identify the clinicopathologic characteristics and prognosis of upper tract urothelial carcinoma (UTUC) patients complicated with aristolochic acid nephropathy(AAN) after radical nephroureterectomy (RNU).

Methods: The clinical data of 42 UTUC patients with AAN (AAN group) and 238 UTUC patients without AAN (NonAAN group) were retrospectively reviewed. All patients received a RNU with excision of bladder cuff. Demographic and clinical data, including preoperative indexes, intraoperative indexes and surgical outcomes were compared.

Results: There were no significant differences in age, tumor location, surgery approach, tumor pathologic grade, stage, the mean operative time and estimated blood loss between the two groups (all $p>0.05$ ). There were more female patients in the AAN group $(p<0.001)$, and $57.1 \%$ were high grade tumors. The AAN group showed a higher complications rate $(p=0.003)$. The median follow-up time was 43.2 months. The AAN group showed a worse estimated 5 -year overall survival rate $(35.1 \%$ vs. $63.0 \%, p=0.014)$, however, no significant difference was found between the two groups with regard to disease specific survival $(63.5 \%$ vs. $81.5 \%, p=0.091)$. Multivariate binary logistic regression analysis showed that AAN was an independent factor related with overall and disease specific survival. 38.9\% of all patients experienced any types of recurrence, and the estimated 5-year recurrence-free survival rate was lower in the AAN group ( $37.1 \%$ vs. $63.7 \%, p=0.001$ ). In the comparison of subgroups stratified by recurrence type, the AAN group had a higher intravesical $(p=0.030)$ and contralateral recurrence rate $(p=0.040)$.

Conclusion: UTUC with AAN occurred more frequently in female patients who were more likely to develop highgrade tumors. However, these patients showed a worse overall survival and a lower recurrence-free survival rate than the other patients. AA-related UTUC might be associate with an increased risk of intravesical and contralateral recurrence after RUN.
\end{abstract}

Keywords: Upper tract urothelial carcinoma, Aristolochic acid, Carcinogenesis, Nephroureterectomy, Survival

\footnotetext{
* Correspondence: 1161449482@qq.com; wangxiaoq@jlu.edu.cn

${ }^{3}$ Department of urology, The First Hospital of Jilin University, Changchun 130021, People's Republic of China

Full list of author information is available at the end of the article
}

(C) The Author(s). 2020 Open Access This article is licensed under a Creative Commons Attribution 4.0 International License, which permits use, sharing, adaptation, distribution and reproduction in any medium or format, as long as you give appropriate credit to the original author(s) and the source, provide a link to the Creative Commons licence, and indicate if changes were made. The images or other third party material in this article are included in the article's Creative Commons licence, unless indicated otherwise in a credit line to the material. If material is not included in the article's Creative Commons licence and your intended use is not permitted by statutory regulation or exceeds the permitted use, you will need to obtain permission directly from the copyright holder. To view a copy of this licence, visit http://creativecommons.org/licenses/by/4.0/. The Creative Commons Public Domain Dedication waiver (http://creativecommons.org/publicdomain/zero/1.0/) applies to the data made available in this article, unless otherwise stated in a credit line to the data. 


\section{Background}

Upper urinary tract urothelial cell carcinoma (UTUC) represents a relatively rare tumor entity and account for $5-10 \%$ of all urothelial carcinomas [1]. The incidence rate has risen worldwide over the past few decades, partly as a result of improvements in UTUC detection and survival $[2,3]$. According to the recent EAU Guidelines, several studies have demonstrated a carcinogenic potential of aristolochic acid (AA) contained in Aristolochia fangchi and Aristolochia clematis [1, 4, 5]. Aristolochic acid is implicated in multiple cancer types, sometimes with very high mutational burdens, especially in UTUCs [6].

Chinese herbal medicine is an important part of traditional Chinese medicine, and it is considered to be an effective alternative treatment all over the world [7]. However, some of these drugs contain nephrotoxins and mutagens in the form of AAs and similar compounds [7, 8]. It causes extensive interstitial fibrosis and severe loss of renal tubules, termed aristolochic acid nephropathy (AAN). UTUC usually occurs after the diagnosis of AAN. AA-associated AAN and UTUCs are prevalent in Taiwan $[4,9]$. A meta-analysis established an odds ratio of 5.97 for developing UTUC after exposure to AA, and this risk may persist for many years (sometimes $>10$ years) after stopping exposure to AA [10].

Compared to UTUC patients without AAN, the oncologic results of UTUC patients with AAN after RNU are unsure. There are only a few reports in the literature about the prognosis of the disease. Cukuranovic et, al. retrospectively analyzed the data of UTUC patients in the Balkans, the results showed that the Balkan endemic nephropathy patients were more likely to develop lower stage and lower grade UTUC. However, the disease specific survival was the same in the Balkan endemic nephropathy patients and control settlements [11]. Other reports indicated that AA exposure was associated with worse disease specific survival, higher intravesical and contralateral recurrence rate $[9,12]$. This study was designed to investigate the clinicopathologic characteristics and oncologic outcomes of UTUC patients with AAN after RNU.

\section{Methods}

\section{Clinical data}

The data of patients diagnosed with UTUC with or without AAN who had undergone RNU and bladder cuff resection on-site were collected from the electronic patient database of the First Hospital of Jilin University. This study was approved by the Ethics Committee of the First Hospital of Jilin University, and written informed consent from patients was obtained. AAN was diagnosed according to previous research: (1) the presence of a definite history of taking AA-containing medications prior to disease onset; (2) the presence of obvious tubular dysfunction, with or without diminished GFR; (3) the absence of recent or long-term ingestion of antibiotics, non-steroidal anti-inflammatory drugs, diuretics or Chinese traditional medicines containing minerals or metals and (4) the absence of evidence of other glomerular or tubulointerstitial diseases caused by infectious or immune diseases; (5) Tubulointerstitial nephropathy was pathologically confirmed by renal biopsy or postoperative specimen examination [13, 14]. From January 2010 to January 2017, electronic records of 42 UTUC patients with AAN (AAN group) and 238 UTUC patients without AAN (non-AAN group) were retrospectively assessed for the recent study.

The UTUC patients were diagnosed by computed tomography (CT) urography, intravenous urography, urinary cytology or ureteroscopy with or without biopsy. Cystoscopies and CT scan were performed to rule out a concomitant bladder cancer and distal metastases. Radical nephroureterectomies were performed by laparoscopic or open strategy, whereby the bladder cuff resections were performed by open extravesical approach in all cases. A single dose of intravesical mitomycin $C$ was given to all patients after the surgery to prevent bladder recurrence. Selected patients who had an advanced disease confirmed by preoperative imaging or postoperative pathology received a neoadjuvant (gemcitabine and cisplatin) or adjuvant chemotherapy (gemcitabine and cisplatin).

\section{Follow-up}

Cystoscopy and urinary cytology was carried out once every 3 months for the first year, and every 6 months thereafter until 5 years. CT urography was performed every 6 months over 2 years and then yearly. A bone scan, chest $\mathrm{CT}$, and magnetic resonance imaging were performed, if necessary. Disease recurrence was defined as local or contralateral recurrence, intravesical recurrence and distant metastasis.

\section{Statistical analysis}

Data are expressed as absolute numbers and percentages, means with $\mathrm{SD}$, or as medians with interquartile ranges as appropriate. IBM SPSS statistics version 20.0 was used for all analyses. For all statistical tests, $P<0.05$ was considered to indicate a significant difference. Chisquare test or Fisher's exact test was used to categorical data and unpaired $t$ test and Mann-Whitney $U$ test for continuous data with and without a normal distribution, respectively. The Kaplan-Meier method was used to calculate survival rates. Multivariate binary logistic regression was used to evaluate if AAN was associated independently with survival from other factors. Recurrence was evaluated from the date of surgery. Tumor 
recurrence-free survival was defined as the interval from surgery to the first appearance of intravesical, local, or contralateral recurrence, and distant metastasis to the end of the study, whichever came first.

\section{Results}

No statistically significant differences were found regarding patients' age, tumor site, surgical approach, pathologic tumor stage and grade between the two groups. There were more female patients in AAN group $(p<$ 0.001 ), whereby $57.1 \%$ of patients in this group had high grade tumours. End-stage renal disease was equally more common in the AAN group than in non-AAN group $(p<0.001)$. No significant differences in terms of operative time and estimated blood loss were observed between the two groups $(142.3 .3 \pm 26.4 \mathrm{~min}$ vs. $146 \pm 32.5$ min, $207.8 \pm 78.3 \mathrm{ml}$ vs. $194.5 \pm 90 \mathrm{ml}, p>0.05$, respectively). Complications included intraoperative bleeding, spleen injury, pleural injury, fever, deep venous thrombosis, incision infection, as well as cardiovascular and cerebrovascular complications. Three patients had a cardiovascular complication and required an intensive care unit stay. According to Clavien-Dindo grading system, the distribution of complications was higher in AAN group $(p=0.003)$ than in non-AAN group of patients (Table 1).

Mean follow-up period was 43.2 (range, 6-72) months. In the AAN group, 10 patients died of metastatic disease and 12 died of other disease. The estimated 5-year overall survival rate and the estimated 5-year disease specific survival rate were 35.1 and $63.5 \%$, respectively. In the Non-AAN group, 35 patients died of UTUC and 43 patients died of other causes. The estimated 5-year overall survival rate and the disease specific survival rate were 63.0 and $81.5 \%$, respectively. The AAN group showed a worse overall survival $(p=0.014)$ (Fig. 1), however, there was no significant difference between the two groups with regard to disease specific survival $(p=0.091)$ (Fig. 2). Multivariate binary logistic regression analysis showed that AAN, T stage, grade, and positive lymph node were the independent factors related with overall and disease specific survival (Table 2).

Three types of tumor recurrence for UTUC were assessed, namely local, intravesical, as well as contralateral. No distant metastases was found before local recurrence. $38.9 \%$ patients experienced any type of recurrence during the follow up. Intravesical recurrence occurred in 61 (AAN, $n=14$; non-AAN, $n=47$ ), local recurrence in 30 (AAN, $n=5$; non-AAN, $n=25$ ) and contralateral recurrence in 18 (AAN, $n=6$; non-AAN, $n=12$ ) patients, respectively. The estimated 5-year recurrence-free survival rate in the AAN group was 37.1 and $63.7 \%$ in the non-AAN group, the recurrence-free survival probabilities differed significantly between the two groups of patients $(p=0.001)$ (Fig. 3). In the comparison of subgroups stratified by recurrence type, the AAN group had a higher estimated 5-year intravesical recurrence-free survival rate $(65.0 \%$ vs $79.4 \%, p=0.03)$ (Fig. 4) and contralateral recurrence rate $(p=0.040)$.

\section{Discussion}

Aristolochic acid represents a carcinogenic, mutagenic and nephrotoxic compound commonly present in members of the plant family Aristolochiaceae and is widely used in Chinese herbs, dietary supplements, slimming pills, and contaminated flour [15-17]. Many studies have shown that exposure to AA is involved in the genesis of the UTUC $[9,12,18]$ and other cancers $[6,19]$; however, its tumorigenic role has yet to be understood. Currently, the main carcinogenic mechanism of $\mathrm{AA}$ is as follows: A:T to T:A transversions occurring in the $5^{\prime}$-CpApG-3' trinucleotide context of the TP53 gene is considered to be the signature mutation of AA $[15,20]$. Genes including $\mathrm{H}$-ras, FGFR3, N-ras and BRCA2 are also involved, particularly in UTUC $[16,21,22]$. To elucidate the role of AA in tumorigenesis, the molecular signature of AA needs to be explored.

The highest incidence of AA-related UTUC worldwide is recorded in Asia [7, 9, 12], with the tumors occurring more frequent in females than males. In our cohort study, the AAN group consists of more female than male patients, and most of these female patients have a history of exposure to AA-related drugs (specifically to treat coronary heart disease and hepatitis) for more than a decade. AAN usually occurs before UTUC, and 14 patients in this study developed UTUC during dialysis. The most common symptoms of UTUC are visible or nonvisible hematuria, flank pain and system syndrome (including anorexia, weight loss, malaise, fatigue, fever, night sweats, or cough). Moreover, hydronephrosis is accidentally detected in patients undergoing health examination for different reasons [1]. For patients with AAN, the possibility of UTUC should be considered when they have hematuria and hydronephrosis. CT urography exhibits the highest diagnostic accuracy of available imaging techniques. In patients with $\mathrm{AAN}$, magnetic resonance imaging is an option when CT urography is not considered because of the renal function. Diagnostic ureteroscopy is used for visualization of the ureter, renal pelvis, and collecting system, as well as for biopsy of suspicious lesions. The procedure is particularly useful in patients with diagnostic uncertainty. Multifocal tumors of AAN-related UTUC may occur; thus, contralateral ureteroscopy is also recommended to rule out lesions.

Radical nephroureterectomy with bladder cuff excision is the standard treatment for UTUC, regardless of surgery approach (open or laparoscopic) [23-26]. Seisen et al. recommended kidney-sparing management as a 
Table 1 Patient characteristics of the two groups

\begin{tabular}{|c|c|c|c|}
\hline Variables & $\operatorname{AAN}(n=42)$ & $\operatorname{NON}-\mathrm{AAN}(n=238)$ & $P$ Value \\
\hline Age (year) & $68.0(52-81)$ & $67.2(32-79)$ & 0.62 \\
\hline Gender, n (\%) & & & $<0.001$ \\
\hline Male & $11(26.2)$ & $142(59.7)$ & \\
\hline Female & $31(73.8)$ & $96(40.3)$ & \\
\hline End-stage renal disease & & & $<0.001$ \\
\hline Yes & $14(33.3)$ & $11(4.6)$ & \\
\hline No & $28(66.7)$ & $227(95.4)$ & \\
\hline Tumor location, n (\%) & & & 0.89 \\
\hline Renal pelvis & $23(54.7)$ & $112(62.7)$ & \\
\hline Ureter & $19(45.3)$ & $126(37.3)$ & \\
\hline Upper & $4(23.1)$ & $36(29.0)$ & \\
\hline Middle & $9(46.2)$ & $60(47.4)$ & \\
\hline Lower & $6(30.7)$ & $30(23.6)$ & \\
\hline Previous bladder tumor n (\%) & & & 0.40 \\
\hline Yes & $5(11.9)$ & $21(9.3)$ & \\
\hline No & $37(88.1)$ & $217(91.7)$ & \\
\hline \multicolumn{4}{|l|}{ Hydronephrosis } \\
\hline Yes & $27(64.3)$ & $156(65.5)$ & 0.87 \\
\hline No & $15(35.7)$ & $82(34.5)$ & \\
\hline pT stage, n (\%) & & & 0.79 \\
\hline pTa & $1(2.4)$ & $7(2.8)$ & \\
\hline pT1 & $19(45.2)$ & $109(45.8)$ & \\
\hline pT2 & $15(35.7)$ & $86(36.1)$ & \\
\hline pT3 & $4(9.5)$ & $26(11.1)$ & \\
\hline pT4 & $3(7.2)$ & $10(4.2)$ & \\
\hline pN stage, n (\%) & & & 0.12 \\
\hline pNO & $38(90.7)$ & $205(86.1)$ & \\
\hline $\mathrm{pN} 1$ & $4(9.3)$ & $33(13.9)$ & \\
\hline Grade, n (\%) & & & 0.11 \\
\hline Low & $18(42.8)$ & $102(43.1)$ & \\
\hline High & $24(57.1)$ & $136(56.9)$ & \\
\hline Surgical approach, n (\%) & & & 0.40 \\
\hline Laparoscopic & $36(85.7)$ & $212(89.1)$ & \\
\hline Open & $6(14.3)$ & $26(10.9)$ & \\
\hline Mean operative time (min) & $142.3 \pm 26.4$ & $146.0 \pm 32.5$ & 0.31 \\
\hline Mean estimate blood loss (ml) & $207.8 \pm 78.3$ & $194.5 \pm 90.0$ & 0.06 \\
\hline Complications (Clavien Grade), n (\%) & & & 0.003 \\
\hline None & $20(47.6)$ & $163(68.5)$ & \\
\hline 1 & $11(26.2)$ & $43(18.1)$ & \\
\hline 2 & $7(16.7)$ & $28(11.8)$ & \\
\hline 3 & $1(2.4)$ & $3(1.3)$ & \\
\hline 4 & $3(7.1)$ & $1(0.4)$ & \\
\hline 5 & $0(0)$ & $0(0)$ & \\
\hline
\end{tabular}




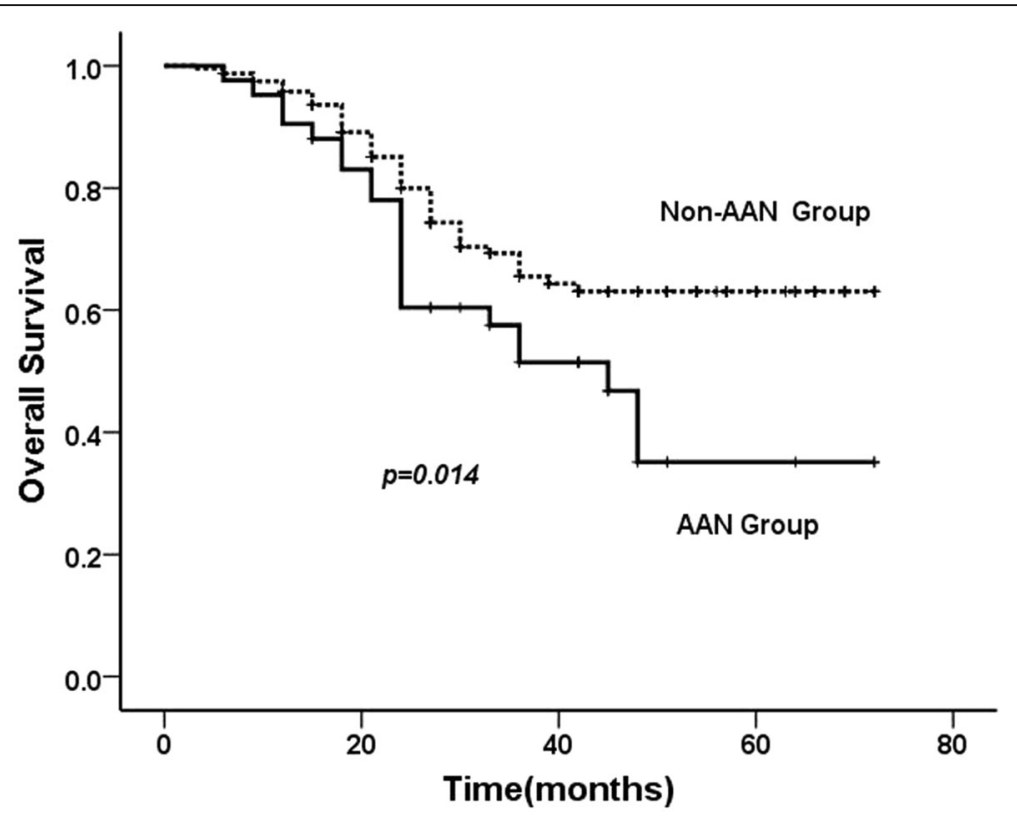

Fig. 1 Cumulative incidence of overall survival following radical nephroureterectomy between AAN and Non-AAN group

treatment option for patients with low-risk tumors [27, 28]. In the current study, patients who underwent kidney-sparing surgery were not enrolled because of the limited sample size. Nortier et al. performed prophylactic removal of native kidneys and ureters in 39 patients with end-stage AAN who were being treated with either transplantation or dialysis. These patients neither manifested clinical symptoms such as hematuria nor exhibited positive findings in preoperative imaging studies. Histological examination of surgical specimens revealed 18 cases of urothelial carcinoma, 19 cases of mild-tomoderate urothelial dysplasia, and 2 cases of normal urothelium. Prophylactic RNU with bladder cuff excision was recommended for patients with end-stage AAN, particularly those with unilateral UTUC [29]. Postoperative intravesical chemotherapy significantly decreases the risk of bladder recurrence after RNU for UTUC $[1,30]$. However, no oncological results regarding intravesical chemotherapy in UTUC patients with AAN have been reported.

One study showed that patients with AAN were more likely to develop lower-stage and lower-grade UTUC in the Balkans, suggesting the reduced potential for malignancy [11]. However, in Taiwan, studies indicated that AA-related UTUC is highly aggressive and typically diagnosed as high-grade and high-stage carcinoma;

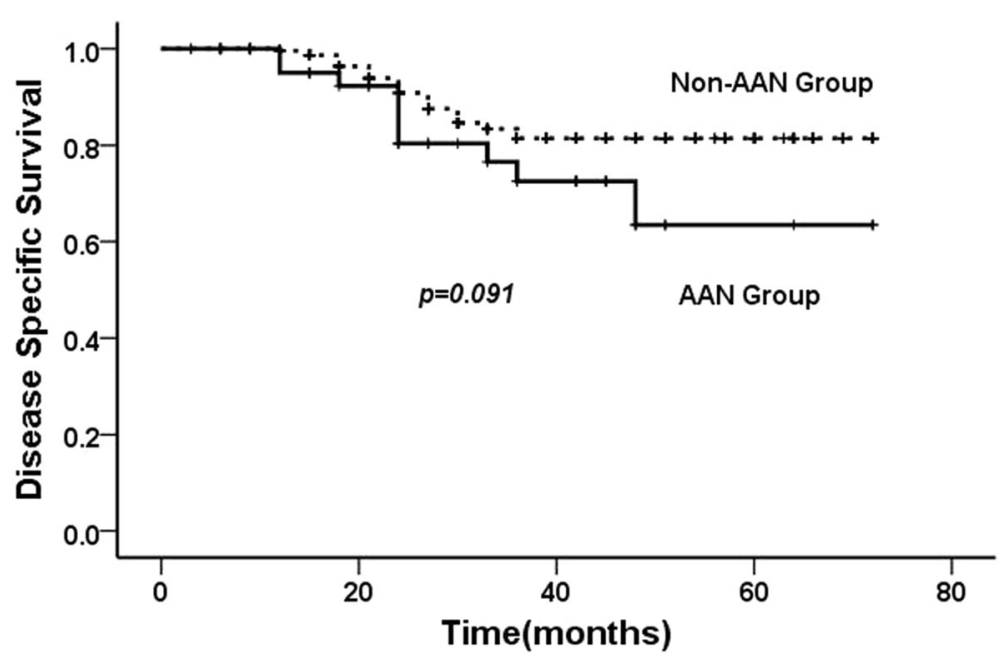

Fig. 2 Cumulative incidence of disease specific survival following radical nephroureterectomy between AAN and Non-AAN group 
Table 2 The risk factors related with the overall and disease specific survival

\begin{tabular}{lllll}
\hline Variables & \multicolumn{2}{l}{ Overall Survival } & & \multicolumn{2}{l}{ Disease Specific Survival } \\
\cline { 2 - 3 } & P value & HR(95\% Cl) & & HR(95\% Cl) \\
\hline Age (years) & 0.483 & $1.012(0.978$ to 1.047$)$ & 0.062 & $1.053(0.899$ to 1.111$)$ \\
Stage(T2-T4 vs Ta,T1) & 0.019 & $2.048(1.637$ to 3.493$)$ & 0.005 & $3.226(1.426$ to 7.297$)$ \\
Lymph node(N1 vs N0) & $<0.001$ & $9.417(2.849$ to 18.461$)$ & 0.003 & $4.860(1.718$ to 13.751$)$ \\
Grade (high vs low) & 0.014 & $2.041(1.159$ to 3.597) & 0.027 & $2.745(1.123$ to 6.712) \\
AAN (yes vs no) & 0.020 & $2.370(1.428$ to 4.902) & 0.020 & $3.061(1.190$ to 7.872$)$ \\
\hline
\end{tabular}

recurrence in the contralateral upper urinary tract is also likely $[9,21]$. Our cohort study showed that $57.1 \%$ of patients with AA-related UTUC had high grade tumors, similar to patients without AAN. The comparison of the estimated 5-year cancer specific survival rate between the two groups showed no significant difference. Thus, exposure to AA may not associated with worse disease specific survival, and the results vary from those of previously published studies [12].

The estimated 5-year overall survival rate was slightly lower, and death from other diseases was higher in the AAN group. Patients with AAN, particularly those undergoing maintenance hemodialysis, might also have various cardiovascular and cerebrovascular diseases related to chronic renal insufficiency. Studies showed that the cardiovascular mortality is $10-20$ fold greater in patients receiving dialysis, relative to that in age and sexmatched controls without chronic kidney disease. Anemia, disordered bone mineral metabolism and oxidative stress also contribute to poor cardiovascular outcomes [31, 32]. Studies have shown that the risk of hospitalized stroke is significantly higher in patients receiving dialysis than in the general population [33].

Some studies have indicated that AA-related UTUCs are highly aggressive and that relapse may occur in the contralateral upper urinary tract $[9,12]$. Our results showed that the estimated 5-year recurrence-free survival rate was significantly lower, and the intravesical and contralateral recurrence rate was higher in the AAN group than in the non-AAN group. These results may be attributed to the following: (1) AA related UTUC may be a multifocal disease. Tumors may occurs simultaneously or sequentially in any part of the urinary tract. Nortier et al. found multifocal tumors in end-stage AAN patients who had received a prophylactic removal of the native kidneys and ureters [29]. Another study determined that tumor multifocality and native AAN are significant independent risk factors affecting the development of initial intravesical recurrence after surgery for primary UTUC [34]. (2) The carcinogenic effects of AA may last for many years even if the drug containing AA is discontinued. Jelakovic's molecular epidemiologic

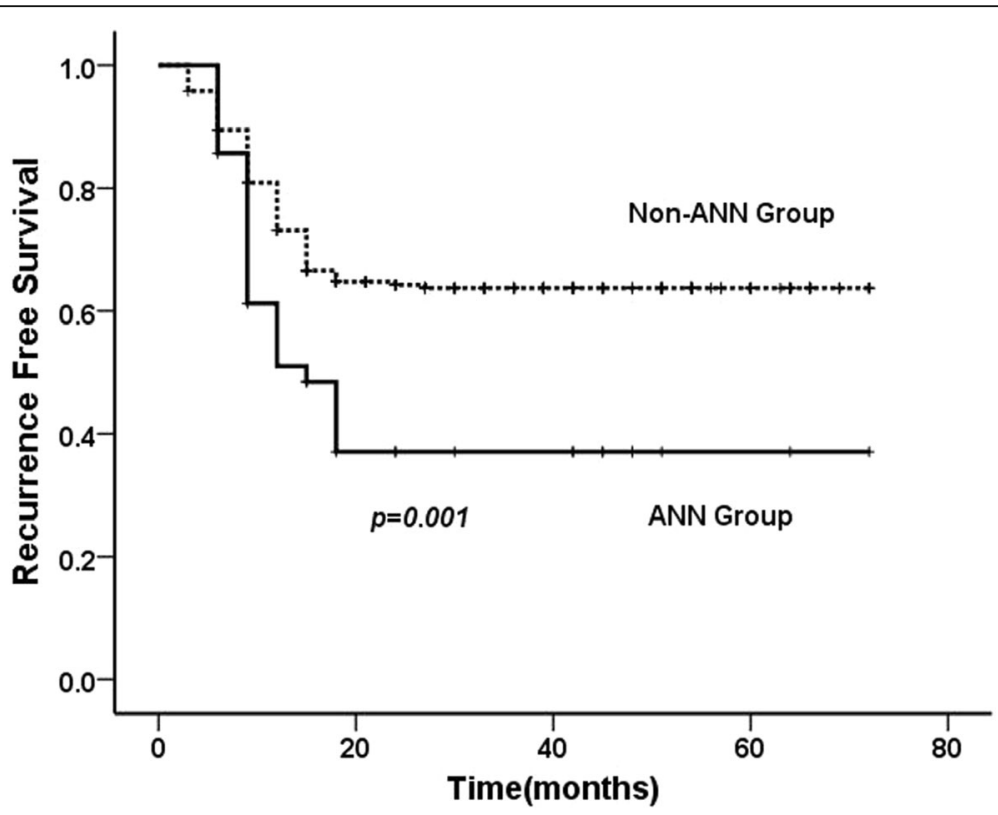

Fig. 3 Kaplan-Meier estimates of recurrence-free probabilities following radical nephroureterectomy between AAN and Non-AAN group 


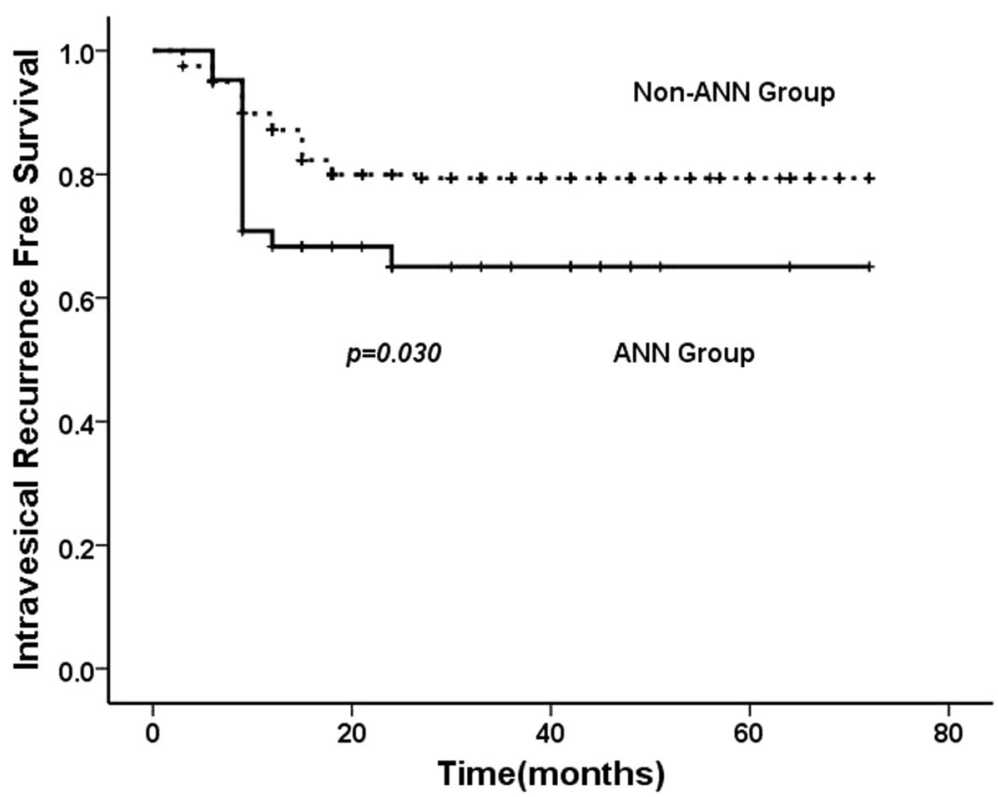

Fig. 4 Kaplan-Meier estimates of intravesical recurrence-free probabilities following radical nephroureterectomy between AAN and Non-AAN group

study reported that AL-DNA adducts and TP53 mutational signature can persist for years after exposure to AA [35]. A higher risk of subsequent development of bladder urothelial carcinoma was also identified in kidney transplant recipients with AAN after bilateral RNU, and it may occur years after AA is discontinued [36]. Owing to the high intravesical and contralateral recurrence rate in patients with AA related UTUC, active follow-up should be conducted after RNU.

The current study has several limitations. First, the small sample sizes and the nature of the retrospective study design and may limit the generalizability of our results. Second, bias in patient enrollment may be present. The patients with a history of exposure to AA but had no AAN were not excluded in the non-AAN group, which can introduce selection bias to our final results. Gene sequencing should be done to identify whether these patients have A:T-to-T:A transversions in TP53. Moreover, we excluded the AA-related patients who received kidney-sparing surgery due to renal insufficiency; these patients might have exhibited more characteristics of AA-related UTUC. Further, the relatively short follow-up time prevented the observation of additional contralateral and intravesical recurrences as well the analysis as long-term cancer specific survival.

\section{Conclusion}

UTUC with AAN occurred more frequently in female patients who were more likely to develop high grade tumors. They had the same estimated 5-year cancerspecific survival rate as that of UTUC patients without
AAN. However, these patients showed a worse overall survival- and a lower recurrence-free survival rate than the other patients. AA-related UTUC might be associate with an increased risk of intravesical contralateral recurrence after RUN. Owing to the limitations of the study, well-designed prospective trials need to be conducted to confirm our findings.

\section{Abbreviations}

AA: Aristolochic acid; AAN: Aristolochic acid nephropathy; CT: Computed tomography; RNU: Radical nephroureterectomy; UTUC: Upper tract urothelial carcinoma

\section{Acknowledgements}

The authors would like to thank all our participants for their gracious participation in this study.

\section{Authors' contributions}

BY and XW designed the research. HS, BX and YH collected the data. WT and SWmade analyzed and interpretation of the data; HS drafted the first draft of the manuscript, CW and XW provided critical revision; all authors give final approval for the manuscript and agree to be accountable for all aspects of the work herein.

\section{Funding}

This study was supported by China Scholarship Council. (No. 201806175061).

\section{Availability of data and materials}

The datasets analyzed during the current study is available from the corresponding author on reasonable request.

Ethics approval and consent to participate

Informed consent was obtained for all participants and studies were approved by the Institutional Review Board at the First Hospital of Jilin University. 


\section{Consent for publication}

Written informed consent was obtained from all cases for publication of this research. A copy of the written consent is available for review by the Editorial team of this journal.

\section{Competing interests}

The authors declare that they have no competing interests.

\section{Author details}

'Department of clinical laboratory, The First Hospital of Jilin University, Changchun 130021, People's Republic of China. ${ }^{2}$ Department of Blood Transfusion, The Second Hospital of Jinlin University, Changchun 131000, People's Republic of China. ${ }^{3}$ Department of urology, The First Hospital of Jilin University, Changchun 130021, People's Republic of China.

\section{Received: 19 October 2019 Accepted: 20 February 2020 Published online: 03 June 2020}

\section{References}

1. Roupret M, Babjuk M, Comperat E, Zigeuner R, Sylvester RJ, Burger M, Cowan NC, Gontero P, Van Rhijn BWG, Mostafid AH, Palou J, Shariat SF. European association of urology guidelines on upper urinary tract urothelial carcinoma: 2017 update. Eur Urol. 2018;73:111-22.

2. Siegel RL, Miller KD, Jemal A. Cancer statistics, 2018. CA Cancer J Clin. 2018; 68:7-30.

3. Chen W, Zheng R, Baade PD, Zhang S, Zeng H, Bray F, Jemal A, Yu XQ, He J. Cancer statistics in China, 2015. CA Cancer J Clin. 2016;66:115-32.

4. Chen CH, Dickman KG, Moriya M, Zavadil J, Sidorenko VS, Edwards KL, Gnatenko DV, Wu L, Turesky RJ, Wu XR, Pu YS, Grollman AP. Aristolochic acid-associated urothelial cancer in Taiwan. Proc Natl Acad Sci U S A. 2012; 109:8241-6

5. Colin P, Koenig P, Ouzzane A, Berthon N, Villers A, Biserte J, Roupret M. Environmental factors involved in carcinogenesis of urothelial cell carcinomas of the upper urinary tract. BJU Int. 2009;104:1436-40.

6. Ng AWT, Poon SL, Huang MN, Lim JQ, Boot A, Yu W, Suzuki Y, Thangaraju S, Ng CCY, Tan P, Pang ST, Huang HY, Yu MC, Lee PH, Hsieh SY, Chang AY, Teh BT, Rozen SG. Aristolochic acids and their derivatives are widely implicated in liver cancers in Taiwan and throughout Asia. Sci Transl Med. 2017:9:eaan6446

7. Yang B, Xie Y, Guo M, Rosner MH, Yang H, Ronco C. Nephrotoxicity and Chinese herbal medicine. Clin J Am Soc Nephrol. 2018;13:1605-11.

8. Nortier $\mathrm{L}$, Vanherweghem $\mathrm{J}$. Renal interstitial fibrosis and urothelial carcinoma associated with the use of a Chinese herb (Aristolochia fangchi). Toxicology. 2002:181-182:577-80.

9. Chen $\mathrm{CH}$, Dickman KG, Huang CY, Moriya M, Shun CT, Tai HC, Huang KH, Wang SM, Lee YJ, Grollman AP, Pu YS. Aristolochic acid-induced upper tract urothelial carcinoma in Taiwan: clinical characteristics and outcomes. Int J Cancer. 2013;133:14-20.

10. Wu F, Wang T. Risk assessment of upper tract urothelial carcinoma related to aristolochic acid. Cancer Epidemiol Biomark Prev. 2013;22:812-20.

11. Cukuranovic R, Ignjatovic I, Visnjic M, Velickovic LJ, Petrovic B, Potic M, Stefanovic V. Characteristics of upper urothelial carcinoma in an area of Balkan endemic nephropathy in South Serbia. A fifty-year retrospective study. Tumori. 2010;96:674-9.

12. Zhong W, Zhang L, Ma J, Shao S, Lin R, Li X, Xiong G, Fang D, Zhou L. Impact of aristolochic acid exposure on oncologic outcomes of upper tract urothelial carcinoma after radical nephroureterectomy. Onco Targets Ther. 2017; 10:5775-82

13. Yang L, Su T, Li XM, Wang X, Cai SO, Meng LQ, Zou WZ, Wang HY. Aristolochic acid nephropathy: variation in presentation and prognosis. Nephrol Dial Transplant. 2012;27:292-8.

14. Gokmen MR, Cosyns JP, Arlt VM, Stiborova M, Phillips DH, Schmeiser HH, Simmonds MS, Cook HT, Vanherweghem JL, Nortier JL, Lord GM. The epidemiology, diagnosis, and management of aristolochic acid nephropathy: a narrative review. Ann Intern Med. 2013;158:469-77.

15. Tao L, Zeng Y, Wang J, Liu Z, Shen B, Ge J, Liu Y, Guo Y, Qiu J. Differential microRNA expression in aristolochic acid-induced upper urothelial tract cancers ex vivo. Mol Med Rep. 2015;12:6533-46.

16. Bara T Jr, Gurzu S, Sugimura H, Bara T, Beleaua MA, Jung I. A systematic review of the possible carcinogenic role of the aristolochic acid. Romanian J Morphol Embryol. 2017;58:41-4.
17. Yang HY, Wang JD, Lo TC, Chen PC. Occupational exposure to herbs containing aristolochic acids increases the risk of urothelial carcinoma in Chinese herbalists. J Urol. 2013;189:48-52.

18. Wang SM, Lai MN, Wei A, Chen YY, Pu YS, Chen PC, Wang JD. Increased risk of urinary tract cancer in ESRD patients associated with usage of Chinese herbal products suspected of containing aristolochic acid. PLoS One. 2014;9: e105218.

19. Hoang ML, Chen CH, Chen PC, Roberts NJ, Dickman KG, Yun BH, Turesky RJ, Pu YS, Vogelstein B, Papadopoulos N, Grollman AP, Kinzler KW, Rosenquist TA. Aristolochic acid in the etiology of renal cell carcinoma. Cancer Epidemiol Biomark Prev. 2016;25:1600-8.

20. Sidorenko VS, Yeo JE, Bonala RR, Johnson F, Scharer OD, Grollman AP. Lack of recognition by global-genome nucleotide excision repair accounts for the high mutagenicity and persistence of aristolactam-DNA adducts. Nucleic Acids Res. 2012:40:2494-505.

21. Chen CH, Dickman KG, Huang CY, Shun CT, Tai HC, Huang KH, Wang SM, Lee YJ, Grollman AP, Pu YS. Recurrence pattern and TP53 mutation in upper urinary tract urothelial carcinoma. Oncotarget. 2016;7:45225-36.

22. Hoang ML, Chen $\mathrm{CH}$, Sidorenko VS, He J, Dickman KG, Yun BH, Moriya M, Niknafs N, Douville C, Karchin R, Turesky RJ, Pu YS, Vogelstein B, Papadopoulos N, Grollman AP, Kinzler KW, Rosenquist TA. Mutational signature of aristolochic acid exposure as revealed by whole-exome sequencing. Sci Transl Med. 2013;5:197ra02.

23. Margulis V, Shariat SF, Matin SF, Kamat AM, Zigeuner R, Kikuchi E, Lotan Y, Weizer A, Raman JD, Wood CG. Upper tract Urothelial carcinoma CollaborationThe upper tract Urothelial carcinoma C. outcomes of radical nephroureterectomy: a series from the upper tract Urothelial carcinoma collaboration. Cancer. 2009:115:1224-33.

24. Ni S, Tao W, Chen Q, Liu L, Jiang H, Hu H, Han R, Wang C. Laparoscopic versus open nephroureterectomy for the treatment of upper urinary tract urothelial carcinoma: a systematic review and cumulative analysis of comparative studies. Eur Urol. 2012;61:1142-53.

25. Shan H, Wang X, Sun Q, Chen Q, Xu B, Hao Y, Xu W. Oncologic results of Retroperitoneoscopic versus open surgery for T2 upper tract Urothelial carcinoma. Clin Genitourin Cancer. 2015;13:568-73.

26. Wang $X Q$, Jiang FM, Chen $Q H$, Hou $Y C$, Zhang HF, Hao $Y Y$, Zhang L, Wang CX. Long-term results of retroperitoneoscopic nephroureterectomy for upper urinary tract transitional cell carcinoma in China. Can Urol Assoc J. 2013;7:E287-92.

27. Seisen T, Nison L, Remzi M, Klatte T, Mathieu R, Lucca I, Bozzini G, Capitanio U, Novara G, Cussenot O, Comperat E, Renard-Penna R, Peyronnet B, Merseburger AS, Fritsche HM, Hora M, Shariat SF, Colin P, Roupret M. Oncologic outcomes of kidney sparing surgery versus radical Nephroureterectomy for the elective treatment of clinically organ confined upper tract Urothelial carcinoma of the distal ureter. J Urol. 2016;195:1354-61.

28. Seisen T, Peyronnet B, Dominguez-Escrig JL, Bruins HM, Yuan CY, Babjuk M, Bohle A, Burger M, Comperat EM, Cowan NC, Kaasinen E, Palou J, van Rhijn BW, Sylvester RJ, Zigeuner R, Shariat SF, Roupret M. Oncologic outcomes of kidney-sparing surgery versus radical Nephroureterectomy for upper tract Urothelial carcinoma: a systematic review by the EAU non-muscle invasive bladder Cancer guidelines panel. Eur Urol. 2016;70:1052-68.

29. Nortier JL, Martinez MC, Schmeiser HH, Arlt VM, Bieler CA, Petein M, Depierreux MF, De Pauw L, Abramowicz D, Vereerstraeten P, Vanherweghem $\mathrm{J}$. Urothelial carcinoma associated with the use of a Chinese herb (Aristolochia fangchi). N Engl J Med. 2000;342:1686-92.

30. Fang D, Li XS, Xiong GY, Yao L, He ZS, Zhou LQ. Prophylactic intravesical chemotherapy to prevent bladder tumors after nephroureterectomy for primary upper urinary tract urothelial carcinomas: a systematic review and meta-analysis. Urol Int. 2013;91:291-6.

31. Johnson DW, Craven AM, Isbel NM. Modification of cardiovascular risk in hemodialysis patients: an evidence-based review. Hemodial Int. 2007;11:1-14.

32. Murali KM, Mullan J, Chen JH, Roodenrys S, Lonergan M. Medication adherence in randomized controlled trials evaluating cardiovascular or mortality outcomes in dialysis patients: a systematic review. BMC Nephrol. 2017;18:42.

33. Seliger SL, Gillen DL, Longstreth WT Jr, Kestenbaum B, Stehman-Breen CO. Elevated risk of stroke among patients with end-stage renal disease. Kidney Int. 2003;64:603-9.

34. Liu YQ, Lu J, Zhao L, Hou XF, Ma LL. Prognostic factors for intravesical recurrence after surgery for upper tract urothelial carcinoma in renal transplant recipients. Beijing Da Xue Xue Bao. 2015;47:605-10. 
35. Jelakovic B, Karanovic S, Vukovic-Lela I, Miller F, Edwards KL, Nikolic J, Tomic K, Slade N, Brdar B, Turesky RJ, Stipancic Z, Dittrich D, Grollman AP, Dickman KG. Aristolactam-DNA adducts are a biomarker of environmental exposure to aristolochic acid. Kidney Int. 2012;81:559-67.

36. Lemy A, Wissing KM, Rorive S, Zlotta A, Roumeguere T, Muniz Martinez MC, Decaestecker C, Salmon I, Abramowicz D, Vanherweghem JL, Nortier J. Late onset of bladder urothelial carcinoma after kidney transplantation for endstage aristolochic acid nephropathy: a case series with 15-year follow-up. Am J Kidney Dis. 2008:51:471-7.

\section{Publisher's Note}

Springer Nature remains neutral with regard to jurisdictional claims in published maps and institutional affiliations.

Ready to submit your research? Choose BMC and benefit from:

- fast, convenient online submission

- thorough peer review by experienced researchers in your field

- rapid publication on acceptance

- support for research data, including large and complex data types

- gold Open Access which fosters wider collaboration and increased citations

- maximum visibility for your research: over $100 \mathrm{M}$ website views per year

At $\mathrm{BMC}$, research is always in progress.

Learn more biomedcentral.com/submissions 